Mul ti obj ective opt i mizati on of a two- pi ece al umi num bever age bot $\mathrm{l}$ e consi dering tactile sensati on of heat and entoossing for mabi l i ty

\begin{tabular}{|l|l|}
\hline 著者 & $\begin{array}{l}\text { Han Ji ng, Yamazaki Koet su, I t oh Ryoui t i , } \\
\text { N shi yama Sadao }\end{array}$ \\
\hline $\begin{array}{l}\text { j our nal or } \\
\text { publ i cat i on t i t l e }\end{array}$ & St r uct ur al and Mul t i di sci pl i nar y Opt i mi zat i on \\
\hline vol une & 32 \\
\hline number & 2 \\
\hline page range & $141-151$ \\
\hline year & $2006-08-01$ \\
\hline URL & ht t p: //hdl . handl e. net /2297/6714 \\
\hline
\end{tabular}


A Paper submitted to Structural and Multidisciplinary Optimization

Title:

Multi-Objective Optimization of a Two-Piece Aluminum Beverage Bottle Considering Tactile Sensation of Heat and Embossing Formability

Jing HAN ${ }^{1}$, Koetsu YAMAZAKI ${ }^{2}$, Ryouiti ITOH $^{1}$ and Sadao NISHIYAMA ${ }^{3}$

${ }^{1}$ Technical Development Department, Aluminum Company, Mitsubishi Materials Corporation, 1500 Suganuma, Oyama-cho, Sunto-gun, Shizuoka 410-1392, Japan

Tel: 81-550-766271, Fax: 81-550-765430, E-mail: hanjing@mmc.co.jp

${ }^{2}$ Graduate School of Natural Science and Technology, Kanazawa University,

Kakuma-machi, Kanzawa, Ishikawa 920-1192, Japan

Tel: 81-76-2344666, Fax: 81-76-2344668, E-mail: yamazaki@t.kanazawa-u.ac.jp

${ }^{3}$ Aluminum Company, Mitsubishi Materials Corporation,

19F Otemachi First Square West, 1-5-1, Ohtemachi, Chiyoda-Ku. Tokyo 100-8117, Japan,

Mailing address of corresponding author:

Koetsu YAMAZAKI

Graduate School of Natural Science and Technology, Kanazawa University,

Kakuma-machi, Kanzawa, Ishikawa 920-1192, Japan

Tel: 81-76-2344666 Fax:81-762344668

E-mail: yamazaki@t.kanazawa-u.ac.jp 


\title{
Multi-Objective Optimization of a Two-Piece Aluminum Beverage Bottle Considering Tactile Sensation of Heat and Embossing Formability
}

\author{
Jing $\operatorname{Han}^{1}$, Koetsu Yamazaki ${ }^{2}$, Ryohichi Itoh $^{1}$ and Sadao Nishiyama ${ }^{3}$ \\ ${ }^{1}$ Technical Development Department, Aluminum Company, Mitsubishi \\ Materials Corporation, \\ 1500 Suganuma, Oyama-cho, Sunto-gun, Shizuoka 410-1392, Japan \\ E-mail: hanjing@mmc.co.jp \\ ${ }^{2}$ Graduate School of Natural Science and Technology, Kanazawa \\ University, Kakuma-machi, Kanzawa, Ishikawa 920-1192, Japan \\ E-mail: yamazaki@t.kanazawa-u.ac.jp \\ ${ }^{3}$ Aluminum Company, Mitsubishi Materials Corporation, 19F Otemachi \\ First Square West, 1-5-1, Ohtemachi, Chiyoda-Ku. Tokyo 100-8117, Japan,
}

\begin{abstract}
This paper deals with a multi-objective optimization of a screw-top beverage bottle for hot vending. The bottle body has temperate touch feeling, and can be embossed easily by axially imposing a cylindrical tube die with rib-shaped inner surface on the outer surface of the bottle body. Initially a contact nonlinear analysis of fingers grasping the bottle is carried out, and the amount of heat transmitted from the hot bottle to the flesh of the finger is then calculated to evaluate the hot touch feeling. Meanwhile, the simulation of the rib-shape embossing process of the bottle body is performed to evaluate the embossing formability of different rib shape designs. Finally,
\end{abstract}


using Response Surface Approximation method and Weighted Sum Approach, a multi-objective optimization on the shape of the rib is performed to obtain temperate touch feeling as well as better embossing formability. The amount of heat transmitted from the optimized rib-shape embossed bottle decreased at least $30 \%$ as compared with that of the regular bottle.

Key Word: Embossing Process Simulations, Tactile Sensation of Heat, Response Surface Approximation, Multi-objective / Multidisciplinary Optimization, Finite Element Analyses

\section{Introduction}

A two-piece (2-Pc) screw-top aluminum beverage bottle is produced by adding necking and screw forming processes to the front end of 2-Pc regular can body that is produced by the usual can body making method. Since the 2-Pc screw-top aluminum beverage bottles have advantages of resealabilty, high recyclability, wider billboard as well as good productivity, they have been attracted more consumers in Japan and are being set to take on international markets (Nishiyama 2002; Ueno 2003). In winter, 
beverages are expected being offered hot. However, when aluminum bottles are warmed up to about $60^{\circ} \mathrm{C}$ in vending machines, they are too hot to be held by hand due to the high thermal conductivity of aluminum. Therefore, in developing the aluminum beverage bottles for hot vending, it is also necessary to take the tactile sensation of heat into consideration. In order to make aluminum bottles adaptable to hot vending market, two ways are developed. As shown in Fig.1, one way is to wrap bottle bodies with a printed PET label to reduce the thermal conductivity, and the other one is to add ribs to the bottle wall by an embossing process. The ribs can reduce the amount of heat transmitted to the finger and the air gap between the embossed body and the PET label can weaken further the heat transfer. On the other hand, finite element analyses have been performed to predict surface deformations of the fingertip (Srinivasan and Dandekar 1996), and geometry and a structural model of the fingertip pulp supported by experimental data have been developed to predict the force-displacement and force-contact area responses of the human fingertip during contact with a flat, rigid surface (Serina et al.1998). Moreover, the surface shape design method that took the tactile sensation into consideration has been proposed and the surface temperature has been used to present warmness of the surface (Suzuki and Nishihara 2004). However, we cannot find any works on trying to apply the finite element method to simulate the 
configuration change of the human fingertip when grasping an object and then to evaluate the tactile sensation of heat numerically.

Regarding embossing process, there are two methods to produce the rib-shape embossed bottles. The first method, rotary embossing method, is to emboss the bottle body by rotating a pair of male and female dies against each other with the bottle body being located over the female die. This embossing method can provide better quality, however poor productivity. The second method, axial embossing method, is to emboss the bottle by axially imposing a cylindrical tube die with the rib-shaped inner surface on the outer surface of the bottles. This method can assure good productivity because the necking, screw forming and embossing processes can be finished by only one horizontal-axis rotary machine, however, the quality is dependent on the shape of ribs and the forming condition. In the sheet forming area, structural optimization techniques have been applied to optimize the process parameters in order to obtain better formability or better quality (Hoon and Kim 2001; Ohata et al.2004).

Recently, the Response Surface Approximation (RSA) method is widely used to carry out nonlinear optimization based on the finite element analysis. As the absorber component of cars, cylindrical shells have been optimized to absorb more crushing energy during car crashing (Yamazaki and Han 1998). As crushable beverage cans, 
cylindrical shells have also been triangulated and optimized for recycling after drinking (Han et al. 2004). In order to optimize effectively a design problem with many design variables in complex geometrical relations, the Design Variable Progressive Optimization method based on RSA is proposed and applied to optimize the bottom of 2-Pc aluminum beverage bottles (Han et al. 2005). Since practical optimization in engineering design problems usually have more than one objective and disciplinary, multi-objective / multidisciplinary optimization techniques have been developed at a rapidly increasing pace (Kim and Weck 2004; Yun et al. 2001; McAllister and Simpson 2003; Manning 2004). However, no attempts in multi-objective and multidisciplinary optimum designs are tried to improve the beverage cans / bottles considering simultaneously the human feeling and sheet-metal formability.

The objective of this study is to develop a rib-shape embossed bottle body for hot vending. The bottle body conducts less heat, hence better touch feeling is expected, and can also be embossed easily using the axial embossing method, hence better productivity and quality are expected. A contact analysis of fingers grasping the bottle body is carried out first, and the amount of heat transmitted from the hot bottle to the flesh of the finger is then calculated to evaluate the touch feeling. Meanwhile, the 
simulation of the rib-shape embossing process of the bottle body is performed to evaluate the embossing formability of different rib shape designs. Finally, on the basis of the numerical evaluations on the touch feeling and embossing formability, RSA method and Weighted Sum approach in structural optimization techniques are applied to perform a multi-objective optimization on the shape of the rib to obtain better touch feeling as well as better embossing formability.

\section{Numerical Analysis of the Tactile Sensation of Heat}

In order to evaluate numerically the touch feeling of the finger when holding the hot beverage bottle, finite element analyses of the tactile sensation of heat are performed. Numerical analyses of the tactile sensation of heat include contact deformation analyses and heat transfer analyses between the finger and rib-shape embossed bottle body, as shown in Fig.2. In the contact analyses, the fingertip is contacted with the mountain of the rib, and a distributed load $p$ toward the bottle is applied to the upper surface of the finger model. The deformed configuration of the finger obtained in the contact analysis is then used in the heat transfer analyses. Figure 3 shows the cross sections of the fingertip and rib-shape embossed bottle body. The complex structure of 
the inside of the finger is neglected and the cross section of the finger model is simplified by taking $25 \mathrm{~mm}$ from the fingertip and $8 \mathrm{~mm}$ from the contact point. The embossed body of sixteen ribs is considered in this paper, i.e., $A_{1}=22.5^{\circ}$. The values of radii used for the analysis of the tactile sensation of heat are $R_{\mathrm{a}}=32 \mathrm{~mm}, R_{\mathrm{b}}=33.15$ $\mathrm{mm}$. The material constants of the finger are assumed as: Young's modulus $E=100$ $\mathrm{MPa}$, Poisson's ratio $\mathrm{v}=0.45$, specific heat $c=3400 \mathrm{~J} /(\mathrm{kg} \cdot \mathrm{K})$, thermal conductivity $\lambda=0.5 \mathrm{~W} /(\mathrm{m} \cdot \mathrm{K})$. The finger model is descritized into four-node quadrilateral elements, and the embossed bottle is assumed as a rigid body of $60^{\circ} \mathrm{C}$. The initial temperature of the finger is set as $35^{\circ} \mathrm{C}$ and the temperature of the nodes on the upper surface of the finger model are fixed as $37^{\circ} \mathrm{C}$. The finite element code, MSC.MARC, is used to simulate the configuration change of the finger and to calculate the amount of heat transmitted from the hot bottle to the flesh of the finger when grasping the embossed bottle body. In order to identify the contact heat transfer coefficient between the finger and the bottle body, the temperature change in fingertip when grasping the hot bottle was calculated using several different values of the contact heat transfer coefficient to fit the experimental measurements of time and temperature. The contact heat transfer coefficient between the finger and the bottle body was finally identified as $46 \mathrm{~W} /\left(\mathrm{m}^{2} \cdot \mathrm{K}\right)$. 
In order to gain a deeper understanding of the influence of rib dimensions $A_{2}, A_{3}$ and $A_{4}$ to the tactile sensation of heat, Model M0 with no embossing process and nine embossed body Models listed in Table 1 are analyzed. The value of $A_{4}$ was calculated using Eq.(1),

$$
A_{4}=\pi-\beta+A_{2} / 2
$$

where,

$$
\beta=\arcsin \left(R_{a} \sin \alpha / \sqrt{R_{a}{ }^{2}+R_{b}{ }^{2}-2 R_{a} R_{b} \cos \alpha}\right) \quad \text { and } \alpha=\left(A_{1}-A_{2}-2 A_{3}\right) / 2 \text {. }
$$

It is clear that with the angle $A_{2}$ or $A_{3}$ increasing, $A_{4}$ increases and the slope of the mountain and valley of the rib becomes steeper.

Table 1. Dimensions of embossed body models

\begin{tabular}{c|c|c|c}
\hline Model & $A_{2}\left({ }^{\circ}\right)$ & $A_{3}\left({ }^{\circ}\right)$ & $A_{4}\left({ }^{\circ}\right)$ \\
\hline \hline M0 & -- & -- & -- \\
\hline M1 & 1.5 & 1.5 & 17.89 \\
\hline M2 & 1.5 & 3.5 & 20.35 \\
\hline M3 & 1.5 & 5.5 & 25.26 \\
\hline M4 & 3.5 & 1.5 & 19.92 \\
\hline M5 & 3.5 & 3.5 & 23.36 \\
\hline M6 & 3.5 & 5.5 & 30.57 \\
\hline M7 & 5.5 & 1.5 & 22.35 \\
\hline M8 & 5.5 & 3.5 & 27.26 \\
\hline M9 & 5.5 & 5.5 & 38.23 \\
\hline
\end{tabular}


Since the force required for holding the bottle body is dependent on the weight of the bottle filled with beverage as well as the friction coefficient between the finger and printed bottle body, contact simulations are performed when five levels of the load, $p=$ 1.5, 2.5, 3.5, 4.5 and 5.5MPa, are applied to the finger model, respectively. The amount of heat transmitted from the bottle in a unit time is calculated using Eq.(2),

$$
Q=c \cdot \sum_{i=1}^{n} A_{i} \cdot\left(\bar{T}_{i}-\bar{T}_{i 0}\right)
$$

where, $n$ is the number of elements, $A_{i}$ is the area of the element $i$, and $\bar{T}_{i 0}$ and $\bar{T}_{i}$ are the initial mean temperature and the mean temperature at a unit time of element $i$, respectively. The ratio of the amount of heat transmitted from the hot bottle is calculated as $\delta=Q / Q_{0}$, where $Q_{0}$ is the amount of heat transmitted from the bottle model M7 when $p=2.5 \mathrm{MPa}$ is applied to the finger model. The heat transfer analysis results at 0.03 second are compared in Fig.4 for all models. It is obvious that all embossed bottle body models transfer less heat to the finger than the un-embossed cylindrical body Model M0 does, when the same load $p$ is applied to the finger. For example, the amount of heat transmitted from Model M7 is $26.7 \%$ smaller than that of Model M0 when load $p=2.5 \mathrm{MPa}$ is applied. The range of the ratio $\delta$ in Fig.4 tells us that the influence of the level of load $p$ decreases with the value of $A_{2}, A_{3}, A_{4}$ increasing. 
Figure 5 shows the temperature distribution of the finger model at 0.03 second when grasping hot bottle models. It is found that the temperature of the finger grasping embossed bottle body is lower than that of un-embossed bottle body. We observed that with the load $p$ increasing, the configuration of the flesh of the finger grasping embossed bodies changes in three steps: (1) covering the top of the mountain of the rib as shown in Fig. 5(a); (2) climbing downward along the side wall of the rib as shown in Fig. 5(b); and (3) arriving the valley of the rib as shown in Fig.5(c). In the first step, with $A_{2}$ decreasing or $A_{4}$ increasing, the contact area $S$ between the finger and bottle body decreases. In the second step, $A_{4}$ influences the contact area more. As well known, the amount of heat transmitted increases with the contact area increasing. Hence, if the load $p$ is not large enough to enable the flesh of the finger cover down from the top of the mountain, the amount of heat $Q$ transmitted to the finger decreases with $A_{2}$ decreasing. If the load $p$ is large enough to enable the flesh of the finger to climb downward the mountain, $Q$ decreases with $A_{4}$ increasing. This is why the amount of heat $Q$ of Model M3 is smaller than that of Model M6 when $p=2.5 \mathrm{MPa}$, and larger than that of Model M6 when $p$ is increased to 4.5 MPa. In the third step, the contact area increases rapidly. This is the reason why $Q$ of Model M3 increases much when load $p$ becomes 5.5 MPa. 
From the comparison of the amount of heat transmitted from the hot bottle body, it is clear that the sharper the mountain of the rib is, the smaller the contact area becomes and then the less the heat is transmitted. It is concluded that the rib-shape of the embossed bottle of relatively small value of $A_{2}$ as well as large value of $A_{4}$ has better touch feeling.

\section{Simulations of the Rib-Shape Embossing Process}

Figure 6(a) shows the analysis model of the axial embossing process. Nonlinear finite element code, MSC.MARC, is used to simulate the cylindrical tube die with rib-shaped inner surface imposing axially on the outer surface of the bottle body. To grasp the influence of the internal pressure $q$ of bottles to the embossing process, simulations with and without the internal pressure are performed. The dimensions of the bottle body and die are illustrated in Fig. 6(b), (c), respectively. The length of the die model is $35 \mathrm{~mm}$. Since the bottle body is axisymmetric, a 1/4 model is descritized into 4-node quadrilateral shell elements. The sidewall thickness of the bottle body is $0.13 \mathrm{~mm}$. The material model used is an elasto-plastic von Mises material with isotropic hardening. Young's modulus $E=70 \mathrm{GPa}$, Poisson's ratio $v=0.33$ and 
yielding stress $\sigma=260 \mathrm{MPa}$ are assumed for the bottle body. The die is treated as a rigid body, and $R_{\mathrm{c}}=32 \mathrm{~mm}, R_{\mathrm{d}}=33.15 \mathrm{~mm}$. The number of ribs is specified as 16 , i.e., $A_{1}=22.5^{\circ}$.

The embossing process simulations are performed using four kinds of die models, Model N1 $\left(A_{2}=1.5^{\mathrm{o}}, A_{3}=5.5^{\circ}\right), \mathrm{N} 2\left(A_{2}=5.5^{\mathrm{o}}, A_{3}=1.5^{\circ}\right)$, Model N3 $\left(A_{2}=3.5^{\mathrm{o}}, A_{3}=\right.$ $\left.5.5^{\circ}\right)$ and Model N4 $\left(A_{2}=1.5^{\circ}, A_{3}=2.5^{\circ}\right)$. Figure 7 shows the embossed bottle body models, and Fig. 8 shows the radial positions of nodes at a section with an original axial distance $l_{1}=20.5 \mathrm{~mm}$ from the shoulder side. It is observed that if there is no internal pressure $q$ applied to the bottle during the axial embossing process, the embossed bottle body dented much when using dies like Model N1 and N3 with a relatively large value of $A_{3}$. And the smaller the value of $A_{2}$ is, the more the embossed body dented and the worse the embossing formability becomes. However, by applying the internal pressure $q$ to the bottle during the axial embossing process, the embossed shape can be improved much even though the shape of ribs is not good for axially embossing.

The mean radii of the mountain and valley of the rib-shape embossed bottle body, $R_{1}$ and $R_{2}$, are used to evaluate the axial embossing formability. The larger the radius difference $\Delta R=R_{1}-R_{2}$ is, the higher the rib is and the better the embossing property is evaluated. Moreover, $R_{1}$ and $R_{2}$ are not expected to be too small. 


\section{Multi-Objective Optimization of the Rib Shape}

On the bases of the numerical analyses of the tactile sensation of heat and the axial embossing process simulations, the hot touch feeling and embossing formability of the bottle with ribs can be evaluated quantitatively. Since the dimensions of ribs influence the touch feeling as well as the embossing formability, it is necessary to perform a multi-objective optimization subject to the rib dimension constraints. The problem is then posed as:

Design variables: $X=\left\{x_{i}\right\}, \quad i=1, \ldots, n \quad(n:$ the number of design variables)

$$
\begin{array}{ll}
\text { Minimize: } & f_{1}=\frac{Q(X)}{Q_{0}}, \\
f_{2} & =\frac{\Delta R_{0}}{R_{1}(X)-R_{2}(X)}, \\
\text { Subject to: } \quad g_{1}=1-R_{1}(X) / R_{1 \min } \leq 0, \\
g_{2}=1-R_{2}(X) / R_{2 \min } \leq 0, \\
x_{i}{ }^{L} \leq x_{i} \leq x_{i}^{U}, \quad i=1, \ldots, n
\end{array}
$$

where, $f_{1}$ is for evaluating the hot touch feeling and $f_{2}$ is for evaluating the embossing formability. $R_{1 \min }, R_{2 \min }$ are the allowable minimum values of the mean radii $\left(R_{1}, R_{2}\right)$ of the mountain and valley of the rib-shape embossed bottle body; $Q_{0}$ and $\Delta R_{0}$ are 
scalars. $x_{i}^{U}$ and $x_{i}{ }^{L}$ are the upper and lower bounds on design variable $i$, respectively.

Figure 9 shows the flowchart of the multi-objective optimization of a beverage bottle considering tactile sensation of heat and embossing formability. The RSA method is applied to approximate response surfaces and an appropriate approach is selected to solve the multi-objective optimization problem. At first, design variables and levels are defined and design points are assigned by an orthogonal array in the design-of-experiment technique. The numerical analyses of the tactile sensation of heat and embossing process simulations are then carried out for all design points. On the basis of the numerical results, approximate functions of the amount of heat $(Q)$, the mean radii $\left(R_{1}, R_{2}\right)$ of mountains and valleys of the embossed bottle are constructed by orthogonal polynomials in terms of design variables. According to the property of objective function space, an appropriate approach of the multi-objective optimization is then selected to minimize the objective function subjected to the constraints. This optimization process is repeated until the given convergence condition is satisfied.

As a numerical example, dimensions $A_{2}$ and $A_{3}$ of the rib are selected as design variables, and the initial design space of design cycle 1 is defined as listed in Table 2. The optimization problem is considered when the distributed load $p=2.5 \mathrm{MPa}$ and 
internal pressure $q=0 \mathrm{MPa}$. The amount of heat $Q$ transmitted from Model $\mathrm{M} 7$ is adopted as $Q_{0}$, and the radius difference $\Delta R$ of the bottle embossed by using Model $\mathrm{N} 2$ is adopted as $\Delta R_{0}$. Figure 10 shows the embossing process simulation results. It is found that at design points with $A_{3}=5.5^{\circ}$, the bottle body dented much, so the response surface is not necessary to be constructed. In order to get more accurate response surfaces in the second design cycle, the upper bound of design variable $A_{3}$ is reduced to $3.5^{\circ}$ as tabulated in Table 2 . On the basis of numerical analysis results of the tactile sensation of heat and the axial embossing process, the response surfaces are approximated as shown in Fig.11. If the constraints are given as $R_{1 \min }=33.05 \mathrm{~mm}$, $R_{2 \min }=31.91 \mathrm{~mm}$, the objective function space can be calculated by gradually changing the value of design variables in equal intervals $\left(\Delta A_{2}=\Delta A_{3}=0.1^{\circ}\right)$ within the design space, as illustrated in Fig.12. It is obvious that the Pareto front is a convex curve. Therefore, the Weighted Sum approach of the multi-objective optimization techniques is applied to optimize the embossed bottle considering both of the touch feeling and the embossing formability. The multi-objective optimization problem of the bottle is then formulated as

$$
\text { Minimize: } \quad f=w_{1} \cdot f_{1}+w_{2} \cdot f_{2} \text {, }
$$

subject to the constraints. The weight coefficients $w_{1}$ and $w_{2}$ are defined as 
$w_{1}+w_{2}=1,0 \leq w_{1}, w_{2} \leq 1$. The series of Pareto points obtained with the weight increment $\Delta w_{1}=\Delta w_{2}=0.2$ are identified towards the lower left corner of the Fig.12 and are listed in Table 3. According to the embossing method employed as well as the use of the beverage bottles, designers may decide the weight coefficients, $w_{1}$ and $w_{2}$. For example, if the bottle is for hot vending, the touch feeling is then important, give $w_{1}$ a larger value. While, if the embossing formability is necessary to be taken into account more, give $w_{2}$ a larger value. The optimum for $w_{1}=1$ is upper left point $\mathrm{F}$, while the optimum for $w_{1}=0$ is lower right point $\mathrm{A}$ in the graph. Embossing simulation results of Pareto Point $\mathrm{A}\left(w_{1}=0, w_{2}=1\right)$, Point $\mathrm{C}\left(w_{1}=0.4, w_{2}=0.6\right)$ and Point $\mathrm{F}\left(w_{1}=\right.$ $\left.1, w_{2}=0\right)$ are compared in Fig.13. The amount of heat transmitted from the optimized bottle model decreased about $30 \%$ to $35 \%$ as compared with that of the regular bottle. Therefore, it can be concluded that the optimum model has better touch feeling and better embossing formability.

\section{Conclusions}

The hot touch feeling of beverage bottles is evaluated quantitatively by Tactile Sensation of Heat analyses composing the contact deformation analysis and heat 
transfer analysis between the finger and hot bottle body. The axial embossing formability is also evaluated quantitatively by the finite element analysis. Moreover, the effects of the dimension of rib-shape embossed bottles to the hot touch feeling and the embossing formability are investigated. Finally, the Response Surface approximation method and Weighted Sum Approach in multi-objective optimization techniques are applied to optimize the rib-shape embossed bottle in order to make it have temperate touch feeling and good embossing property as expected by designers.

\section{References}

Han, J., Itoh, R., Nishiyama, S. and Yamazaki, K. (2005), Application of Structure Optimization Technique to Aluminum Beverage Bottle Design. Structural and Multidisciplinary Optimization, 29(4), pp.304-311

Han, J., Yamazaki, K. and Nishiyama, S. (2004) Optimization of the Crushing Characteristics of Triangulated Aluminum Beverage Cans. Structural and Multidisciplinary Optimization, 28(1), pp.47-54.

Hoon, H. and Kim, S. (2001) Optimum Process Design in Sheet-Metal Forming With Finite Element Analysis, " Trans. of ASME, Journal of Engineering Materials and Technology, 123(4), pp. 476-481. 
Kim, I. Y. and de Weck, O. L. (2004) Adaptive Weighted Sum Method for Multiobjective Optimization. Proc.10th AIAA/ISSMO Multidisciplinary Analysis and Optimization Conference, AIAA-2004-4322, Albany, New York, In CD-ROM.

Manning, T., Gage, P., Nguyen, J. and Haimes, R. (2004) ComGeom2: A Geometry Tool for Multidisciplinary Analysis and Data Sharing. 10th AIAA/ISSMO Multidisciplinary Analysis and Optimization Conference, AIAA-2004-4303, Albany, New York, In CD-ROM.

McAllister, C. and Simpson, T. (2003) Multidisciplinary Robust Design Optimization of an Internal Combustion Engine. Trans. of ASME, Journal of Mechanical Design, 125(1), pp. 124-130

Nishiyama, S., 2002. Aluminum Can Recycling in a Synthesized Closed-Loop. Corrosion Engineering, 51, pp.381-394

Ohata, T., Nakamura, Y., Katayama, T. and Nakamachi, E. (2003) Development of Optimum Process Design System for Sheet fabrication using response Surface method. Journal of materials processing technology, 143(144), pp.667-672.

Serina, E. Mockensturm, E. Mote Jr. C. and Rempel D. (1998) A Structural Model of the Forced Compression of the Fingertip Pulp. Journal of Biomechanics, 31, 
pp.639-646.

Srinivasan, M. and Dandekar, K. (1996) An Investigation of the Mechanics of Tactile Sense Using Two-Dimensional Models of the Primate Fingertip. Trans. of ASME, Journal of Biomechanical Engineering, 118, pp.48-55.

Suzuki, K., and Nishihara, T. (2004) The Design of Surface Shape of Resin Considering Tactile Sensation. Proc. 3rd China-Japan-Korea Joint Symposium on Optimization of Structural and Mechanical Systems, Kanazawa, Japan, pp.329-334.

Ueno, H. (2003) Drinks Cans with Customer Convenience. Proc. the Canmaker Summit, Singapore, in CD-ROM.

Yamazaki, K. and Han, J. (1998) Maximization of the Crushing Energy Absorption of Tubes. Structural Optimization, 16(1), pp.37-46.

Yun, Y.B., Nakayama, H., Tanino, T. and Arakawa, M. (2001) Generation of Efficient Frontiers in Multi-Objective Optimization Problems by Generalized Data Envelopment Analysis. European Journal of Operational Research, 129(3), pp.586-595. 
Table 2 Design points assigned by orthogonal array $L_{9}$.

\begin{tabular}{c|c|c|c|c}
\hline \multirow{2}{*}{$\begin{array}{c}\text { Design } \\
\text { Point }\end{array}$} & \multicolumn{2}{|c|}{ Design cycle 1 } & \multicolumn{2}{c}{ Design cycle 2 } \\
\cline { 2 - 5 } & $A_{2}\left(^{\mathrm{o}}\right)$ & $A_{3}\left({ }^{\mathrm{o}}\right)$ & $A_{2}\left({ }^{\mathrm{o}}\right)$ & $A_{3}\left({ }^{\circ}\right)$ \\
\hline \hline 1 & 1.5 & 1.5 & 1.5 & 1.5 \\
\hline 2 & 1.5 & 3.5 & 1.5 & 2.5 \\
\hline 3 & 1.5 & 5.5 & 1.5 & 3.5 \\
\hline 4 & 3.5 & 1.5 & 3.5 & 1.5 \\
\hline 5 & 3.5 & 3.5 & 3.5 & 2.5 \\
\hline 6 & 3.5 & 5.5 & 3.5 & 3.5 \\
\hline 7 & 5.5 & 1.5 & 5.5 & 1.5 \\
\hline 8 & 5.5 & 3.5 & 5.5 & 2.5 \\
\hline 9 & 5.5 & 5.5 & 5.5 & 3.5 \\
\hline
\end{tabular}

Table 3 Optimal solutions from Weighted Sum Approach.

\begin{tabular}{c|c|c|c|c|c|c|c|c|c}
\hline $\begin{array}{c}\text { Pareto } \\
\text { Point }\end{array}$ & $w_{1}$ & $w_{2}$ & $\begin{array}{c}A_{2} \\
\left({ }^{\circ}\right)\end{array}$ & $\begin{array}{c}A_{3} \\
\left({ }^{\circ}\right)\end{array}$ & $f_{1}$ & $f_{2}$ & $f$ & $g_{1}$ & $g_{2}$ \\
\hline \hline A & 0.0 & 1.0 & 3.51 & 1.74 & 0.969 & 0.951 & 0.951 & $-2.2 \mathrm{E}-03$ & $-1.2 \mathrm{E}-04$ \\
\hline B & 0.2 & 0.8 & 3.43 & 2.25 & 0.955 & 0.953 & 0.953 & $-2.1 \mathrm{E}-03$ & $-1.1 \mathrm{E}-04$ \\
\hline C & 0.4 & 0.6 & 3.22 & 2.52 & 0.939 & 0.960 & 0.952 & $-1.9 \mathrm{E}-03$ & $0.0 \mathrm{E}+00$ \\
\hline D & 0.6 & 0.4 & 2.59 & 2.78 & 0.925 & 0.975 & 0.945 & $-1.4 \mathrm{E}-03$ & $0.0 \mathrm{E}+00$ \\
\hline $\mathrm{E}$ & 0.8 & 0.2 & 1.73 & 3.29 & 0.916 & 0.998 & 0.932 & $-6.1 \mathrm{E}-06$ & $-6.3 \mathrm{E}-06$ \\
\hline $\mathrm{F}$ & 1.0 & 0.0 & 1.50 & 3.23 & 0.912 & 1.023 & 0.912 & $0.0 \mathrm{E}+00$ & $-3.5 \mathrm{E}-04$ \\
\hline
\end{tabular}




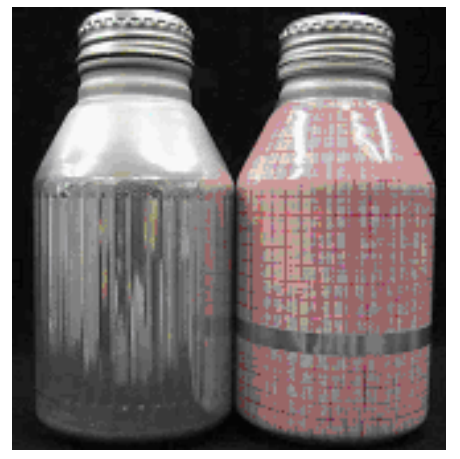

Fig. 1 Bottles with ribs and wrapped with shrink film.

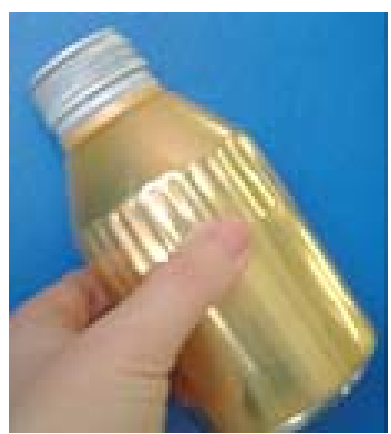

(a) Model

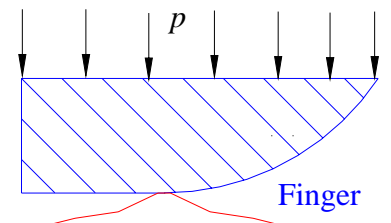

Bottle body

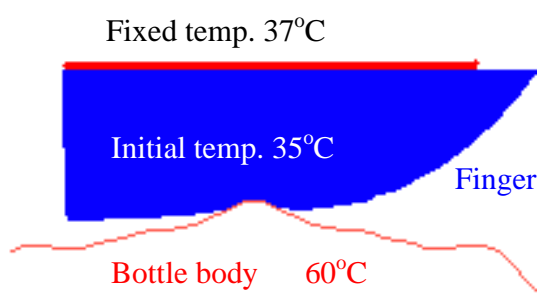

(c) Heat transfer analysis model

(b) Contact analysis model

Fig. 2 Analysis model of tactile sensation of heat. 


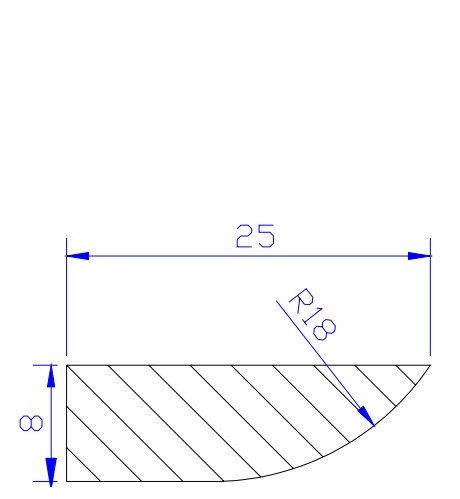

(a) Finger model (unit: mm).

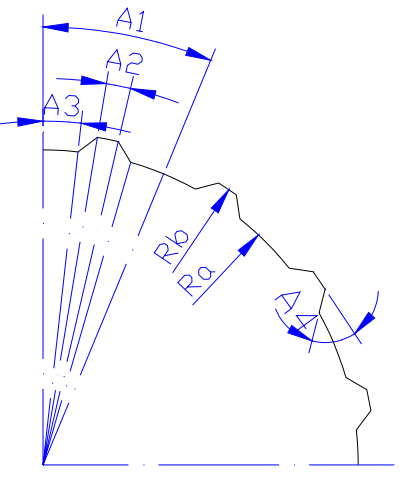

(b) Rib-shape embossed bottle body.

Fig. 3 Cross-sections of fingertip and embossed bottle body.

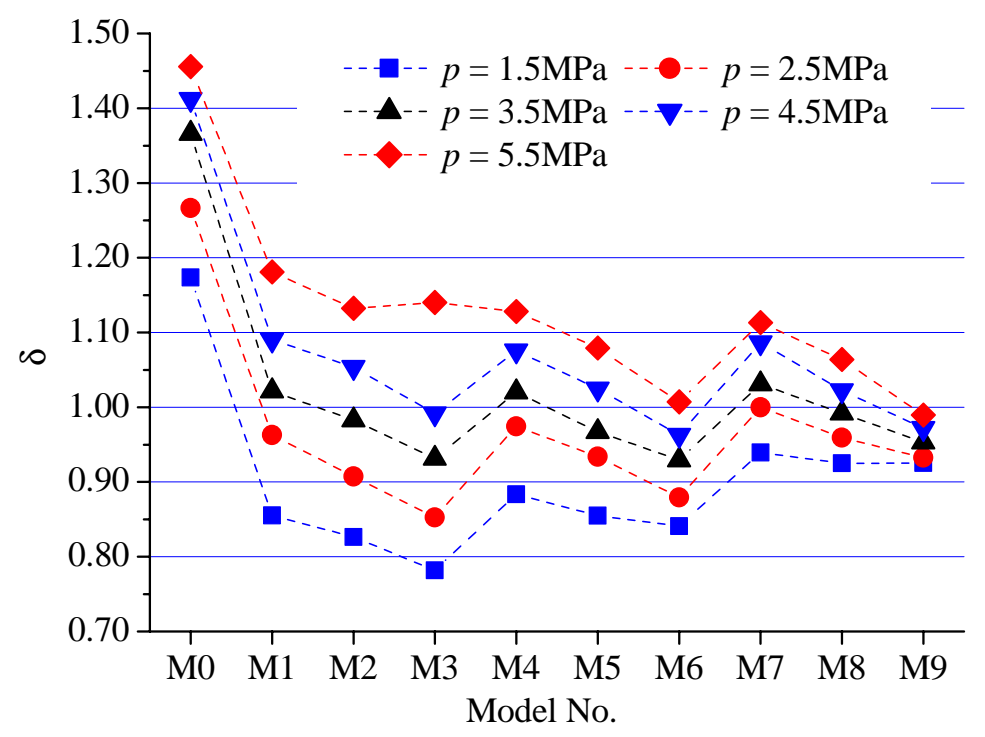

Fig. 4 Heat transfer analysis results at 0.03 second. 


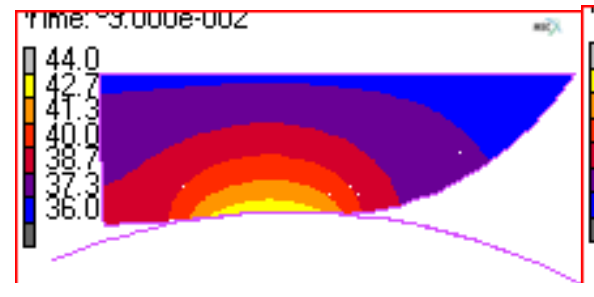

Model M0

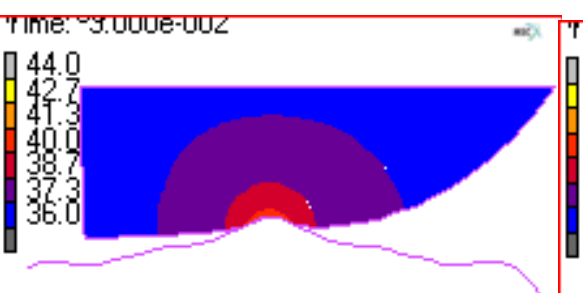

Model M3

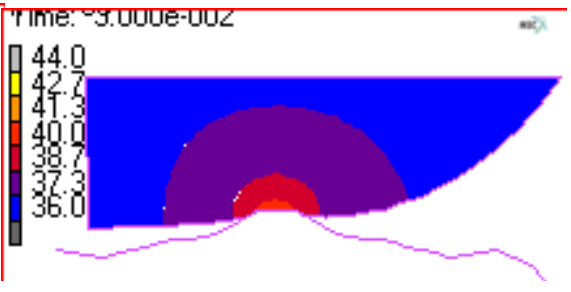

Model M6

(a) $p=2.5 \mathrm{MPa}$

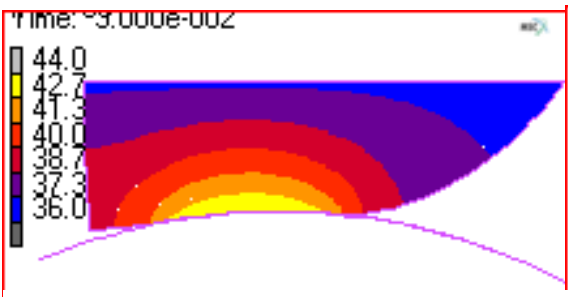

Model M0

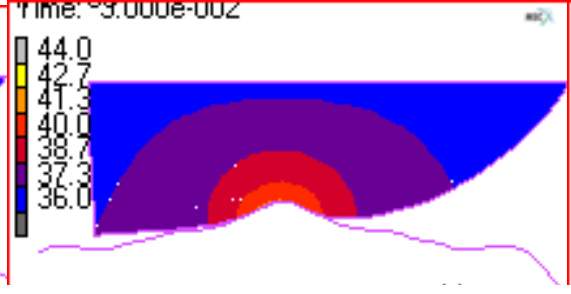

Model M3

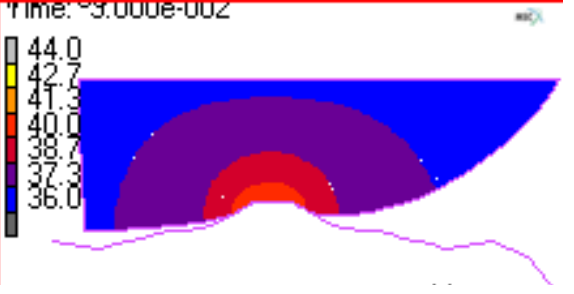

Model M6

(b) $p=4.5 \mathrm{MPa}$

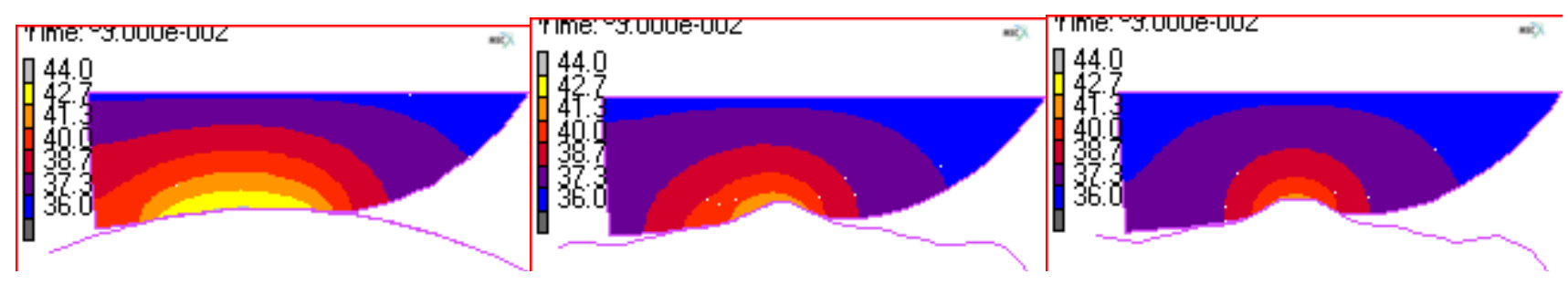

Model M0

Model M3

Model M6

(c) $p=5.5 \mathrm{MPa}$

Fig. 5 Temperature distribution of the finger at 0.03 second. 


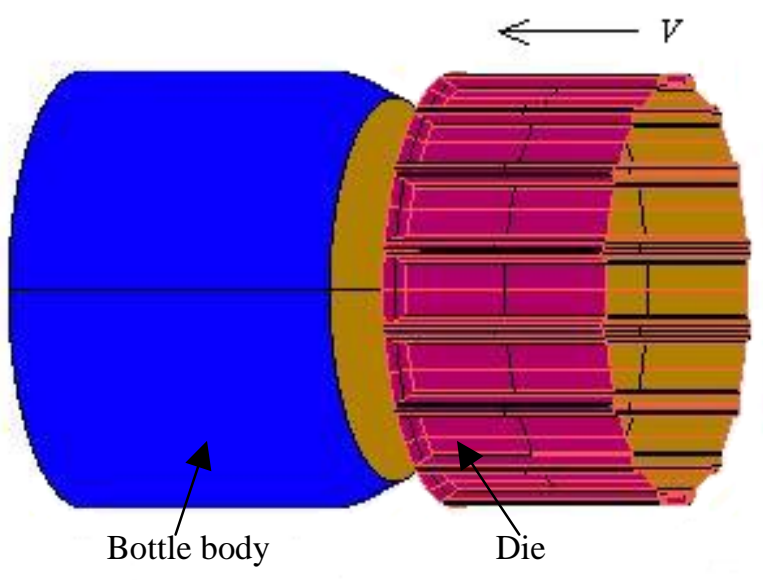

(a) Axial embossing model

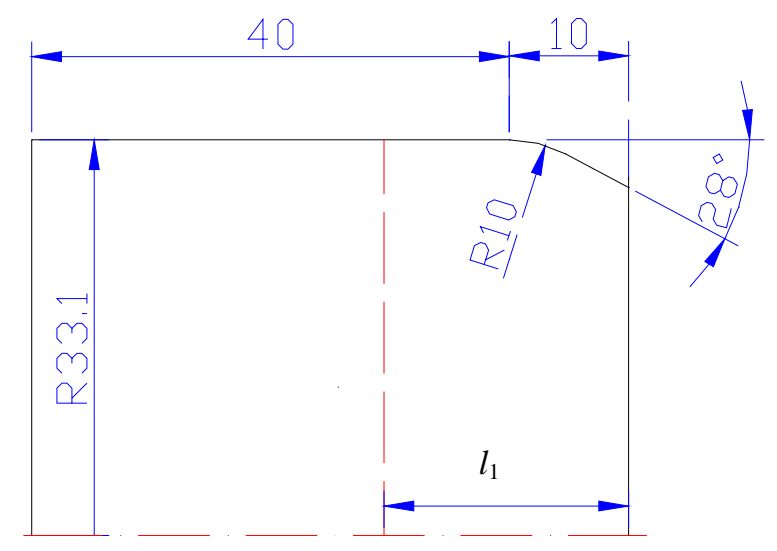

(b) Bottle body model (unit: $\mathrm{mm}$ )

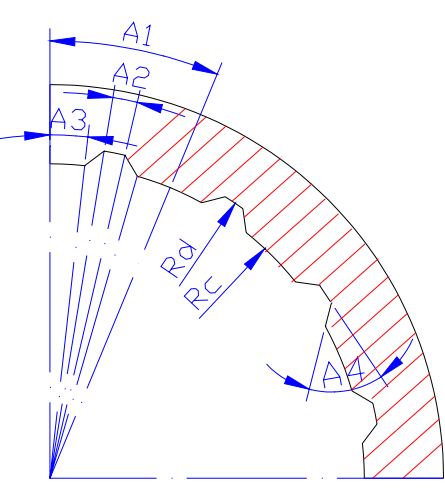

(c) Cross section of die

Fig. 6 Simulation model of embossing process. 


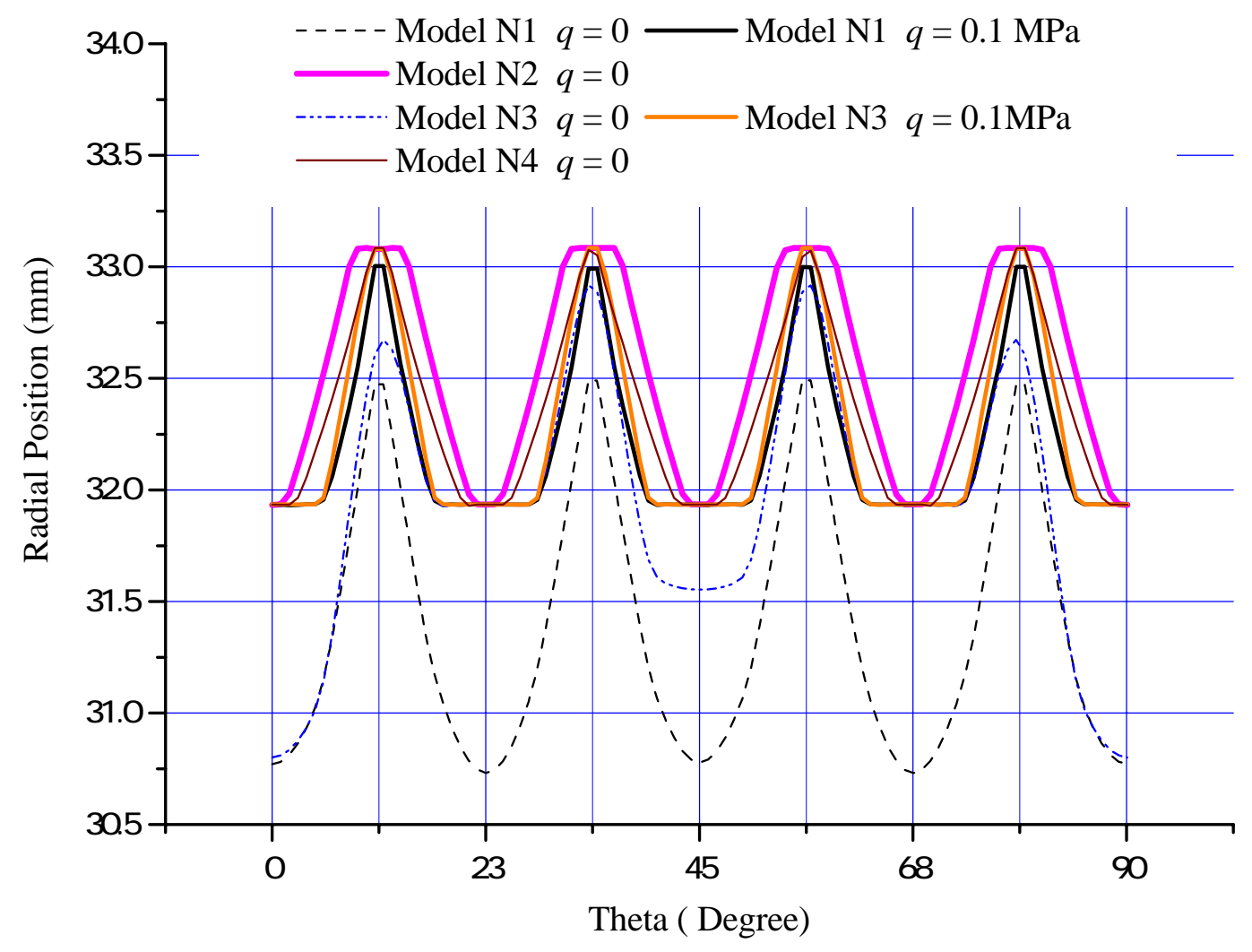

Fig. 7 Simulation results of the embossing process with and without internal pressure. 


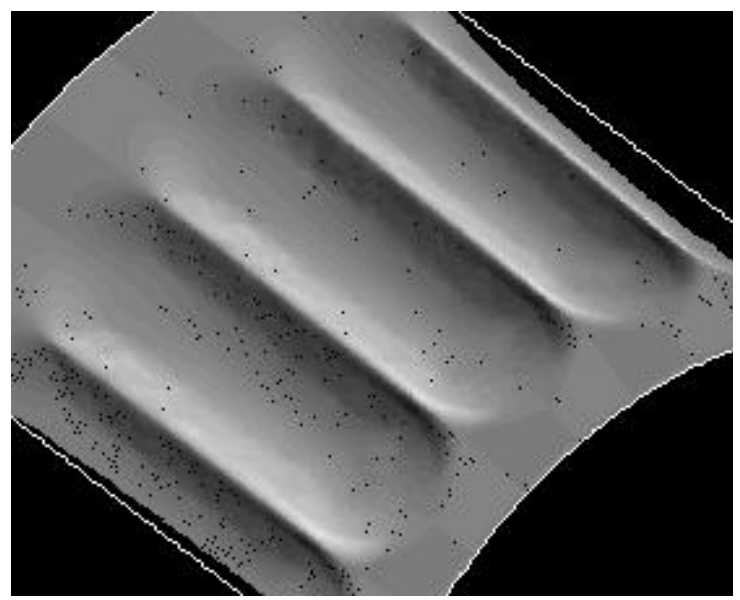

(a) Model N1 $\left(A_{2}=1.5^{\circ}, A_{3}=5.5^{\circ}\right)$

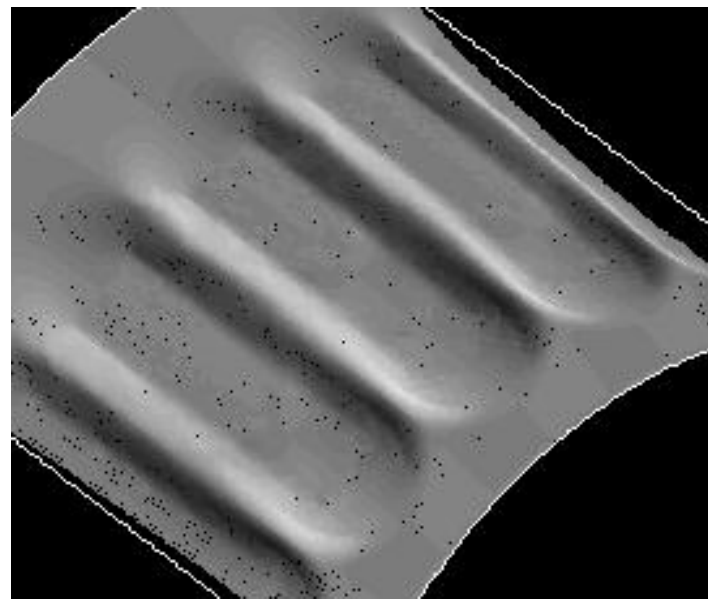

(c) Model N3 $\left(A_{2}=3.5^{\circ}, A_{3}=5.5^{\circ}\right)$

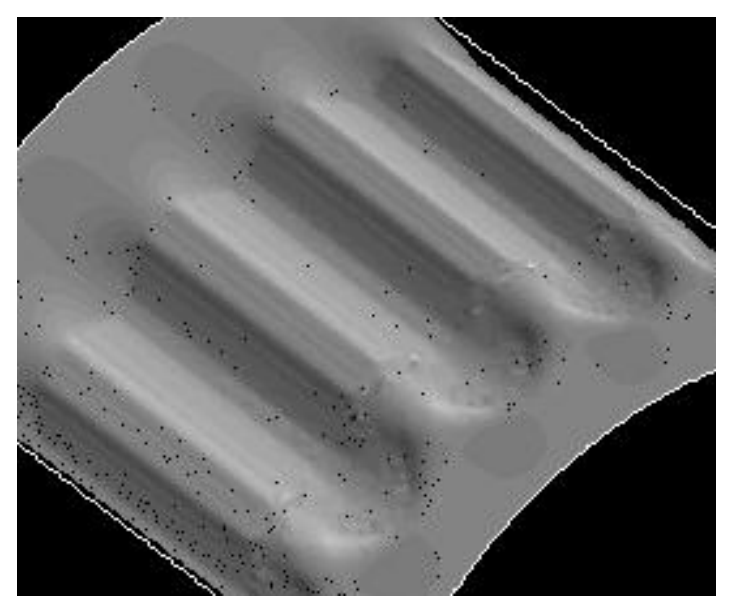

(b) Model N2 $\left(A_{2}=5.5^{\circ}, A_{3}=1.5^{\circ}\right)$

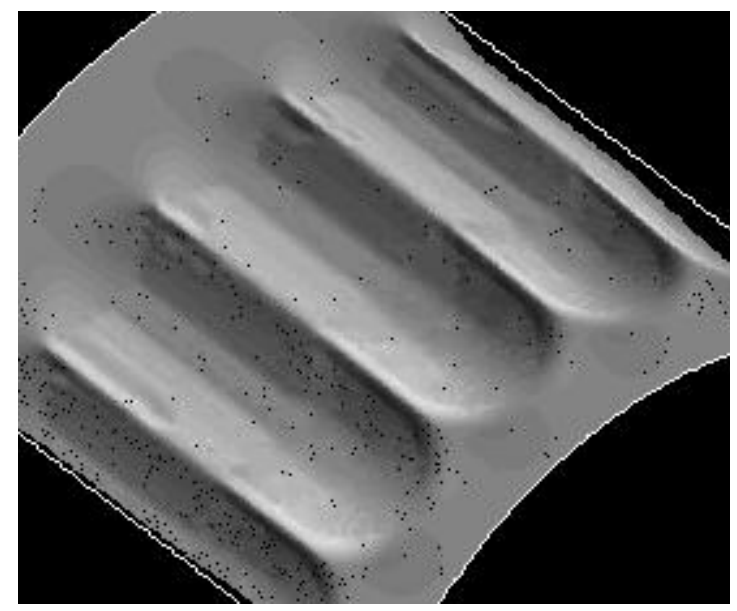

(d) Model N4 $\left(A_{2}=1.5^{\circ}, A_{3}=2.5^{\circ}\right)$

Fig. 8 Rib-shape embossed bottle body ( $q=0 \mathrm{MPa})$. 


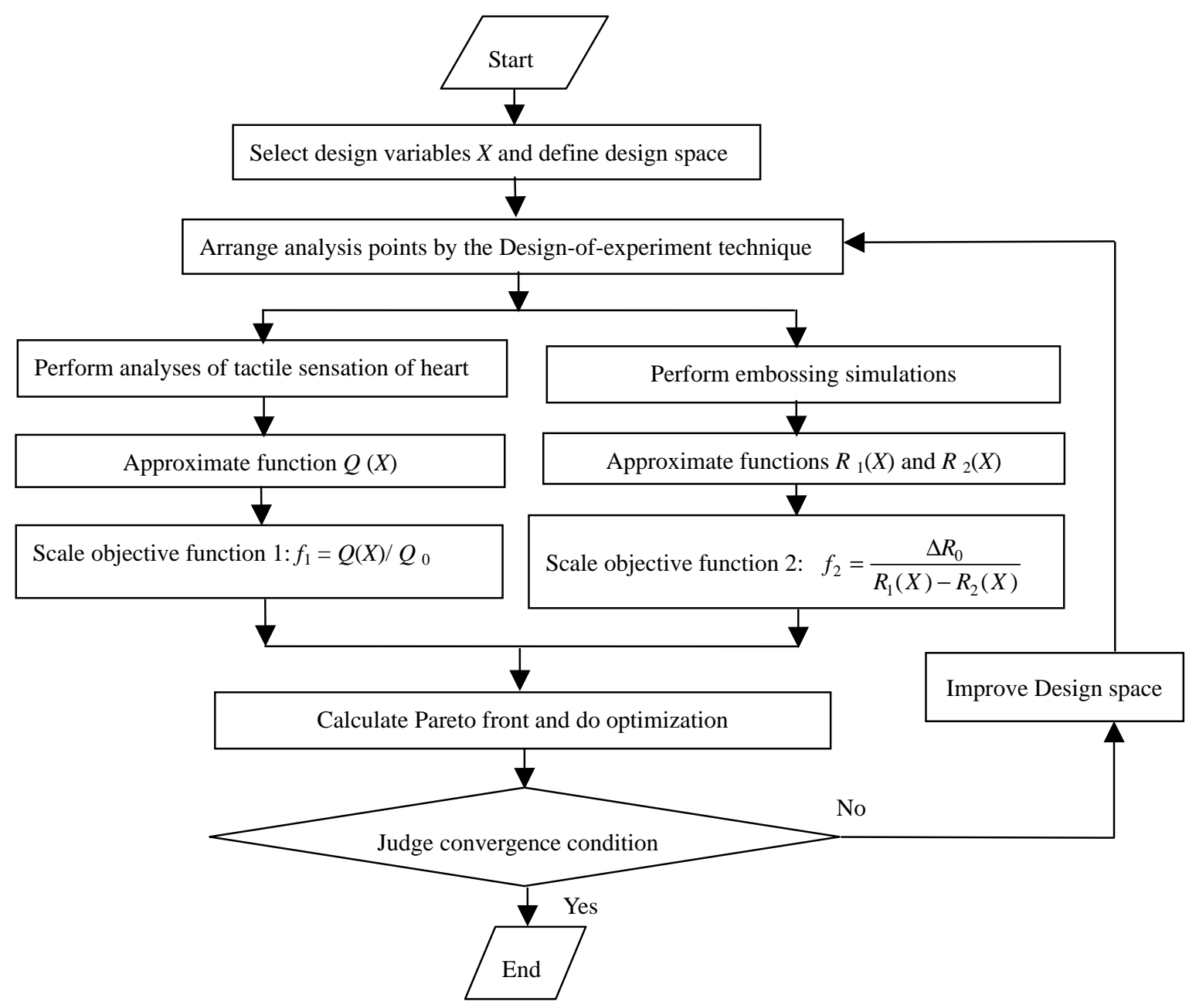

Fig.9 Flowchart of the multi-objective optimization of a beverage bottle considering tactile sensation of heat and embossing formability 


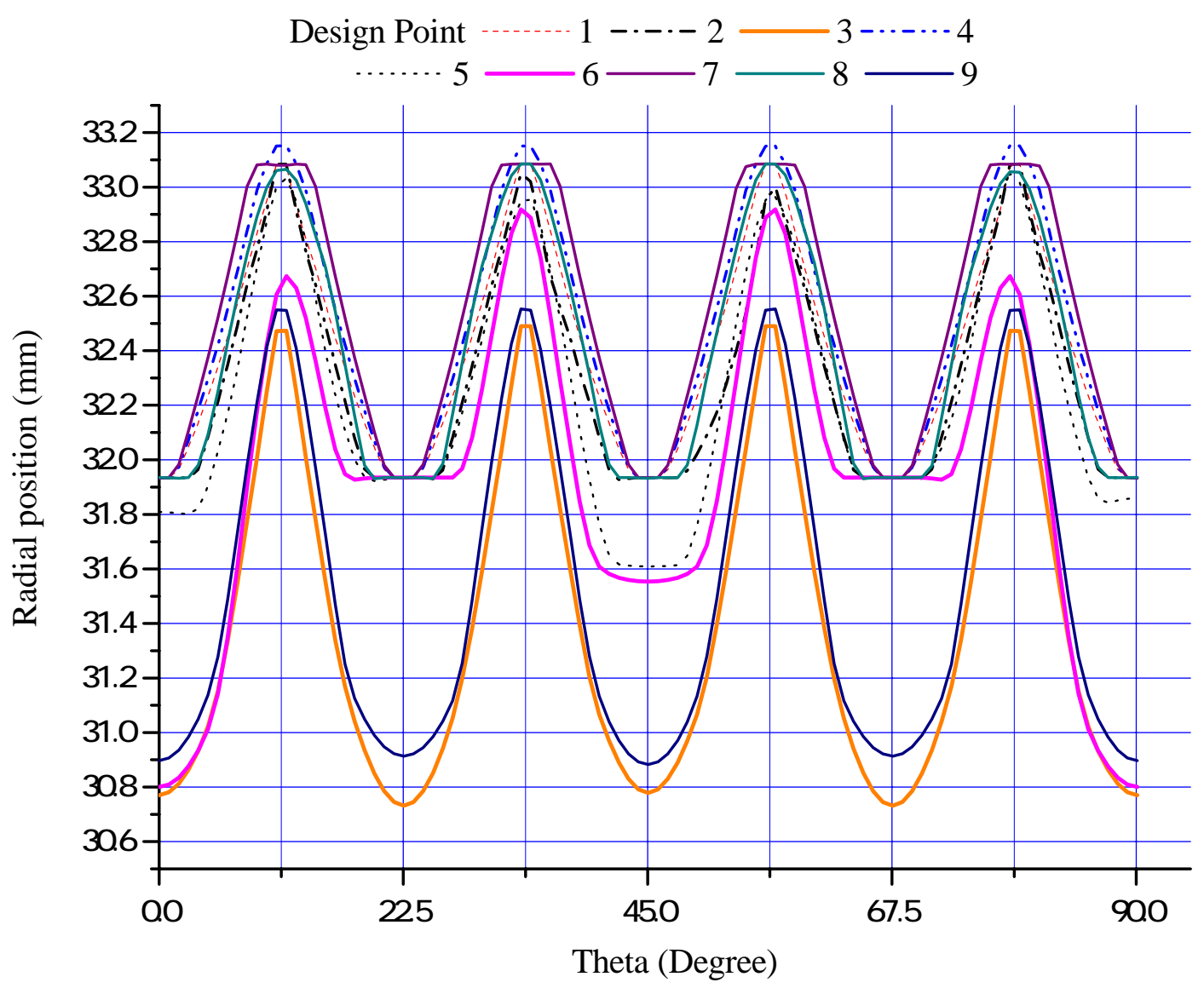

Fig. 10 Embossing process simulation results of design cycle 1. 


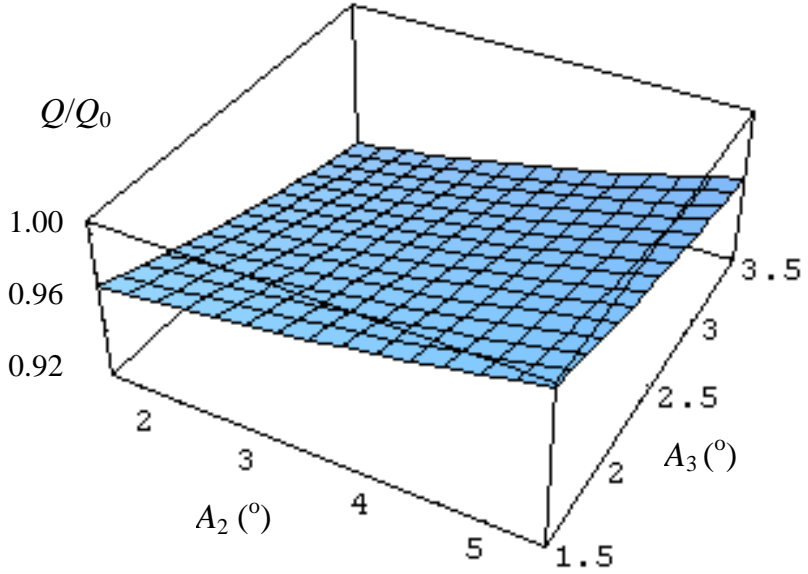

(a)

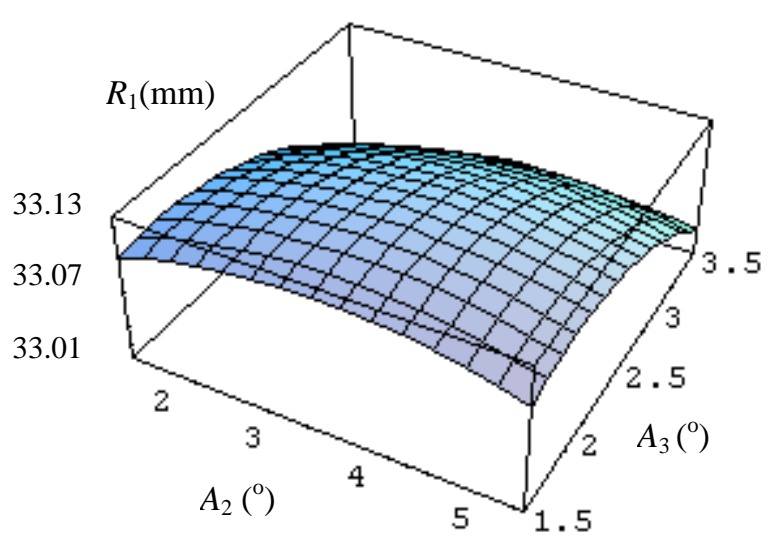

(c)

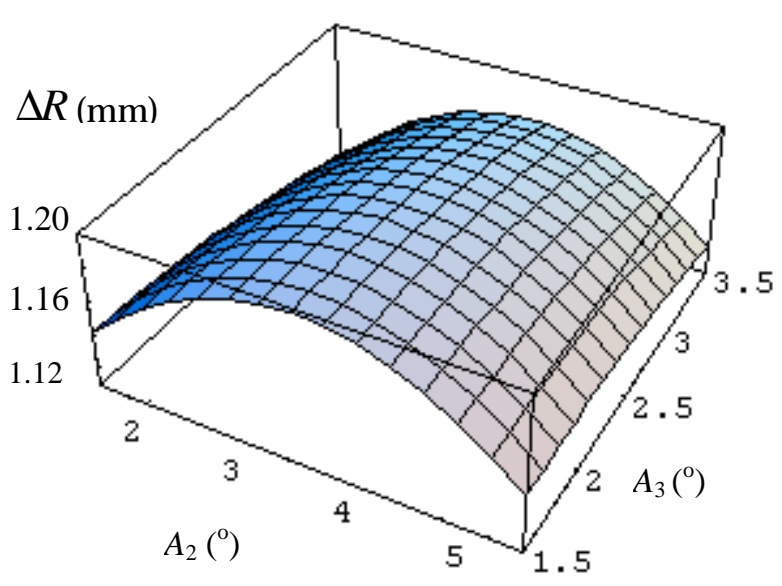

(b)

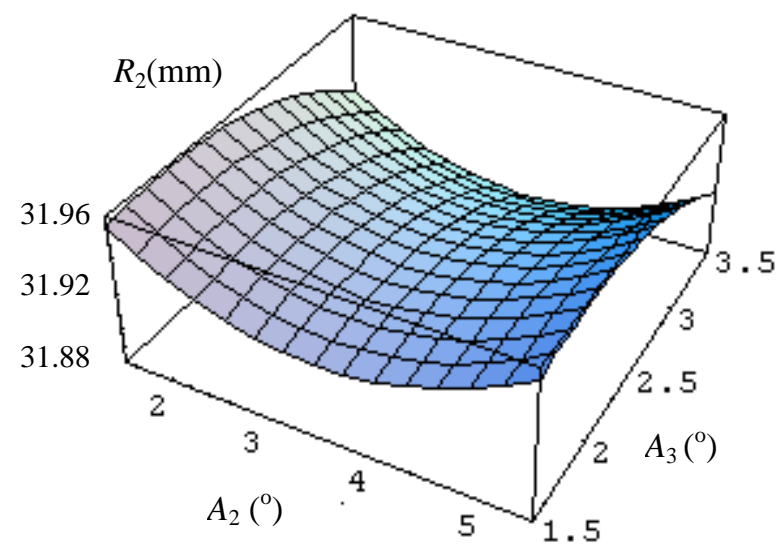

(d)

Fig. 11 Approximate response surfaces in design cycle 2. 


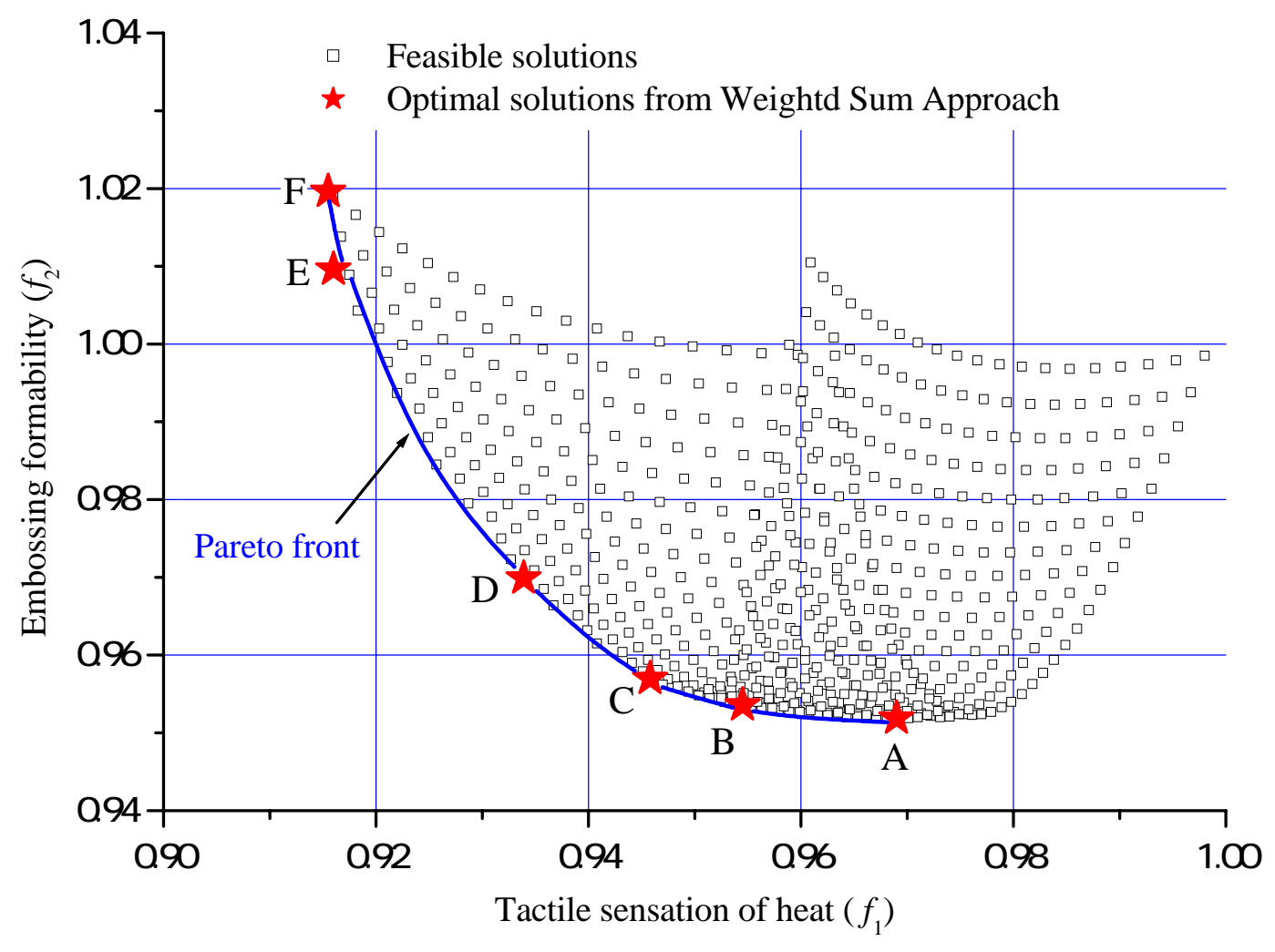

Fig. 12 Objective space of design cycle 2. 


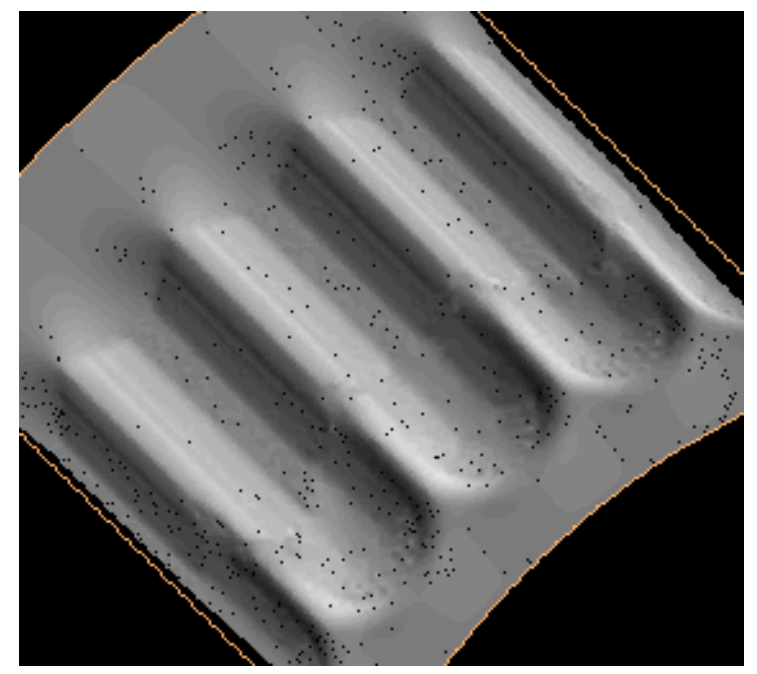

(a) Pareto Point $\mathrm{A}\left(A_{2}=3.51, A_{3}=1.74^{\circ}\right)$

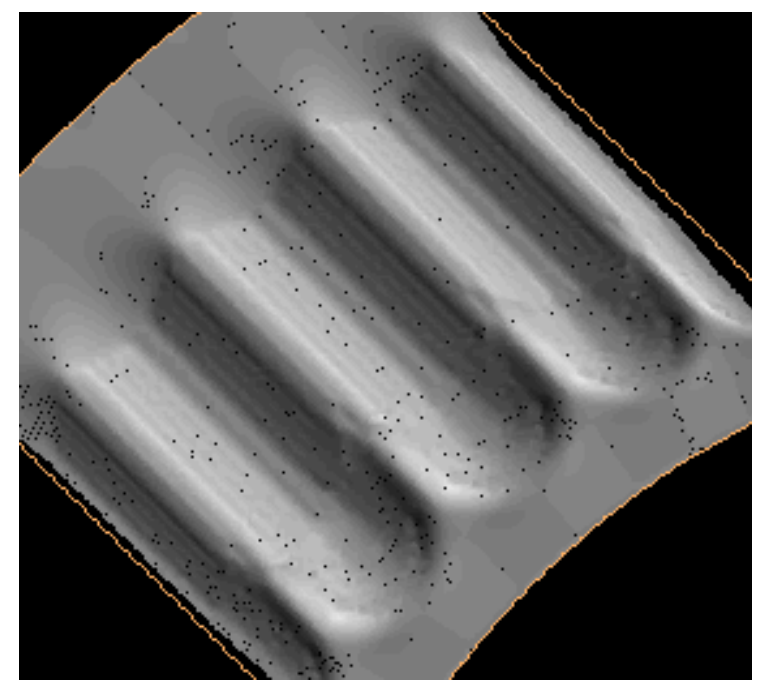

(b) Pareto Point C $\left(A_{2}=3.22^{\circ}, A_{3}=2.52^{\circ}\right)$

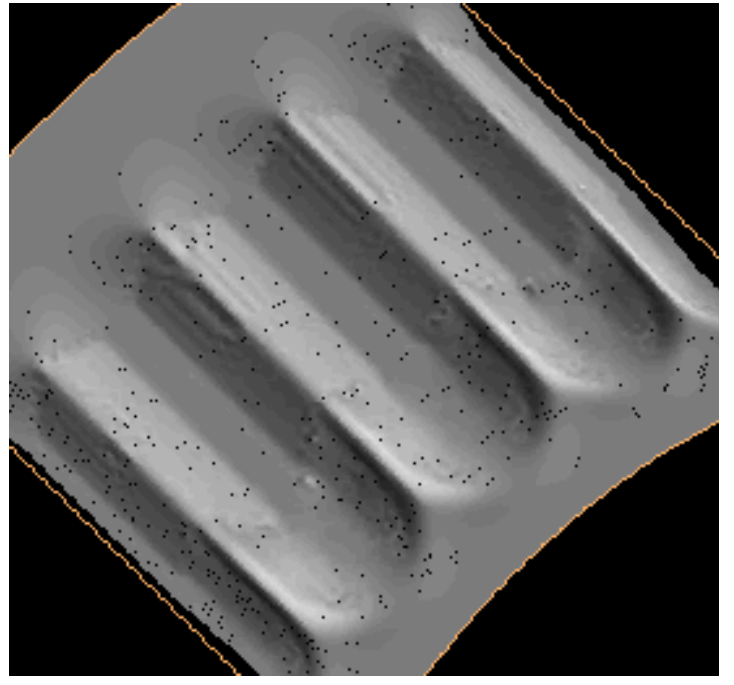

(c) Pareto Point F $\left(A_{2}=1.50^{\circ}, A_{3}=3.23^{\circ}\right)$

Fig. 13 Embossing simulation results of Pareto Points A, C, F. 